\title{
Correction to: Photoelectrochemical performance of dye and semiconductor sensitization on 1-D hollow hexagonal ZnO rods: A comparative study
}

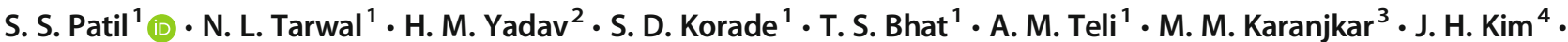 \\ P. S. Patil ${ }^{1}$
}

Published online: 1 April 2019

(C) Springer-Verlag GmbH Germany, part of Springer Nature 2019

Correction to: J Solid State Electrochem (2018)

https://doi.org/10.1007/s10008-018-3995-y

Unfortunately, in the original publication of the article, the Fig. 7 has an oversight. On Y-axis current density is " $\mathrm{uA}$ " rather than "mA". The correct Figure is given below. The authors regret this error.

The online version of the original article can be found at https://doi.org/ 10.1007/s10008-018-3995-y

\footnotetext{
S. S. Patil

satyajeet1396@gmail.com

jinhyeok@chonnam.ac.kr

patilps_2000@yahoo.com

1 Thin Film Materials Laboratory, Department of Physics, Shivaji

University, Kolhapur, Maharashtra 416 004, India

2 Department of Energy and Materials Engineering, Dongguk University, Seoul 04620, South Korea

3 Department of Physics, Vivekanand College, Kolhapur, Maharashtra 416 003, India

4 Department of Materials Science and Engineering, Chonnam National University, Gwangju 500 757, South Korea
}

$\triangle$ J. H. Kim

$\triangle$ P. S. Patil 


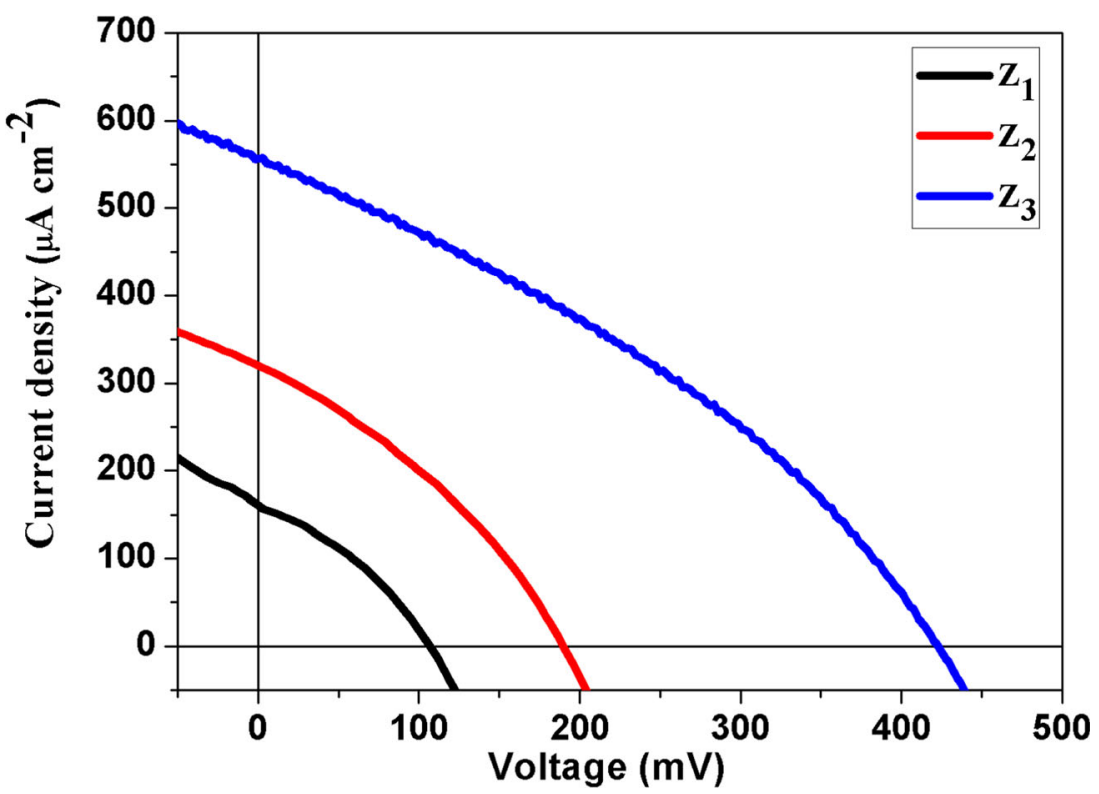

Fig. $7 \mathrm{I}-\mathrm{V}$ measurement of $\mathrm{Z}_{1}, \mathrm{Z}_{2}$ and $\mathrm{Z}_{3}$ thin films

Publisher's note Springer Nature remains neutral with regard to jurisdictional claims in published maps and institutional affiliations. 